\title{
Bioelectrochemical Sysytem: An Eco-Friendly Approach To Generate Electricity Utilizing Plants And Microorganisms
}

KRUTI DAVE ( $\square$ kmd01@ganpatuniversity.ac.in )

Ganpat University

Parth Darji

GANPAT UNIVERSITY

Fenie Gandhi

GANPAT UNIVERSITY

Saumya Singh

GANPAT UNIVERSITY

Digvijaysinh Jadav

GANPAT UNIVERSITY

Research

Keywords: Electricity, fossil, Bioelectricity, MFC, PMFC

Posted Date: October 5th, 2020

DOl: https://doi.org/10.21203/rs.3.rs-64793/v1

License: (c) (1) This work is licensed under a Creative Commons Attribution 4.0 International License. Read Full License 
Bioelectrochemical Sysytem: An Eco-Friendly Approach To Generate Electricity Utilizing Plants And Microorganisms

\author{
Kruti Dave $^{1 *}$, Parth Darji, ${ }^{2}$ Fenie Gandhi ${ }^{2}$, Saumya Singh, ${ }^{2}$ Digvijaysinh Jadav ${ }^{2}$ \\ Department of Biotechnology, Mehsana Urban Institute of Sciences, Faculty of Science, Ganpat University, Gujarat,India ${ }^{1,2}$
}

davekruti2@gmail.com

\begin{abstract}
$\underline{\text { ABSTRACT }}$
With the expanding population, there is increase in an energy demand, which leads to the depletion of non-sustainable energy sources, for example; fossils. As the current situation speaks, the oil deposits are left for mere 53 years, likely with gas i.e. 52 years and with coal 150 years. So, there is an urgent need to find a sustainable source which is cheap and environment friendly, owing to the fact of current energy consumption level is left for merely 230 years. As committed by green alternative, for the future enhancement of the planet, the fossil fuel abandonment is required, and instigation of renewable resources such as Microbial Fuel Cell [MFCs] and Plant Microbial Fuel Cell [PMFCs] should be implemented. MFC is a visionary technique, as it converts wastage into the energy, whereas, PMFC is a new-fangled technique devoid of any climatic conditions and also it requires less investment. By scrutinizing this technique, Bacillus megaterium and sewage material is used in MFCs whereas Azolla and Trigonella foenum is used in PMFCs, which converts chemical energy into electrical energy with the help of electrons flowing from anode to cathode via circuit. The individual setup of each MFCs and PMFCs are examined diurnally for voltage and current gain proceeded by connection of both [MFC and PMFC] in series with LED in between thus gaining the luminance in LED. So assurance is gained by this technique of MFC and PMFC as distinctive energy harvesting technology equipped with; consistency, maintenance and free power for distant future.
\end{abstract}

\title{
Key words: Electricity, fossil, Bioelectricity, MFC, PMFC
}

\section{INTRODUCTION:}

With a developing total populace and increasing welfare, energy request overall world is expanding (Helder et al. 2012). Major of the energy is utilized as electricity and significant commitments in creating electricity originates from the non-sustainable sources of energy for example fossils. As of now utilized petroleum products are unevenly disseminated over the world, are being drained, and are nonrenewable. Excessive utilization of non-renewable energy sources like fossils presents ecological dangers and has brought about the quest for economical sources of energy (Asif and Muneer 2007; Hill et al. 2006).

These days, the requirement for manageable sustainable power source is earnest because of exhaustion of petroleum products, expanding energy utilization, environmental change, and natural pollution. But renewable source of energy should be cheap, environment friendly, sustainable and has multiple advantages for the humans as well as environment (Fargione et al. 2006). Economical elective energy sources that are approached these days all have their disadvantages. They are climate subordinate (wind, sunlight), compete with nourishment/feed creation (some biofuels), or include high investment costs (Huesemann 2006).

Current creation forms for bio-energy, for example, biodiesel or bioethanol often contend with production of food. Deforestation is also significant wellspring of ozone depleting substance discharges on the planet. In this way, to have economical sustainable energy sources, there ought to be no opposition with food production (Pimentel et al. 2009). Wind, geothermal, solar and hydro-electric force without a doubt decline $\mathrm{CO} 2$ impressions; in any case, they have a few drawbacks, for example, transformation, energy-intensive processes, and geographic restrictions (Bombelli et al. 2016).

MFCs or Microbial Fuel Cells have indicated extraordinary guarantee as a unique vitality collecting innovation that can give predictable, support free force for significant stretches of time. It converts the wastage into the energy with no environmental footprint. An MFC is a type of construction where microbes transform the chemical energy provided by the oxidized forms of natural or inorganic compound into ATP i.e. energy by repetitive responses into which the electrons are transferred to a final electron acceptor to form an electrical flow. Throughout time, numerous headways and alterations were done in MFC advances. PMFC was purposed with consolidating a plant at an anode region as the source of substrates for microorganisms (Torres et al. 2009).

A standard MFC comprises of two segments an anode and a cathode, which are parted by a proton exchange membrane. Microorganisms dwell in the anodic segment, where they metabolise organic compounds for example, glucose which goes about as $\mathrm{e}^{-}$benefactor. The process of metabolization of such organic compounds leads to generation of protons and electrons. The electrons then are transferred to the surface of anode. From there, the electrons shift to the cathode from the external electrical circuit, whereas the protons relocate with the help of electrolyte and further by the proton exchange layer. Protons and electrons are utilized in the cathodic chamber by reduction of soluble electron acceptors, such as hexacynoferrate or oxygen or acidic permanganate. The electrical power is obtained when a load is placed on the external electrical circuit between two electrode segments. (Korneel et al. 2004; Behera and Ghangrekar 2009).

Based on structure of MFC it can be separated into two major types : one is a single chambered MFC while another is a dual chambered one. The MFC which is described in the statement above is containing two separate chambers, one cathodic and one anodic chamber. 
Thus, it is known as a dual chambered MFC. Although, the construction which contains only a single chamber in which both the cathode and anode are present in solitary is known as single chambered MFC. (Chae et al. 2009).

A number of assortment of substrates have been utilized in MFC. The substrates do not just impact the necessary organization of the bacterial network in the anode biofilm, yet in addition the MFC execution includes the Columbic productivity and Force thickness. During advancement of this innovation, various substrates having lower molecular weight were utilized as substrates, for example, sugars like glucose, fructose, sucrose, xylose, maltose and trehalose ; organic acids, for example, acetic acid derivation, butyrate, propionate, succinate, malate, lactate, alcohols, for example, methanol and ethanol and inorganic mixes, for example, sulfate. Moreover, some complex sources of carbon present in wastewaters from various sources were likewise tried for generation of bioelectricity (Liu et al. 2004).

So, inside the MFC, microorganisms act like catalysts for breaking down of substrates like sugar and other substrates which are present in their periphery environment and they release a small amount of energy present within those molecules as electrical energy. The usage of MFC as an elective hotspot for power generation is taken into consideration as a proficient, dependable and perfect procedure which uses inexhaustible techniques and does not create any potentially dangerous side effect. Hence, in recent times, MFCs have proven to be a potential technique for recovery purpose and for production of electricity from chemical energy (Logan 2004).

The Plant-Microbial Fuel Cell (PMFC) is an innovation that can possibly be utilized climate free, at wherever on the planet where plants can develop, without rivalry with nourishment or feed creation, and with generally low investment costs (Kaku et al. 2008).

The PMFC yields solar oriented energy to produce electricity by the process of electricity produced by the bacteria via the oxidation of organic compounds which are decomposed by the plants in the rhizosphere. The point of the PMFC is to transfer sun oriented energy into electrical energy by oxidization of rhizodeposits done by electrochemically dynamic microorganisms. Simultaneous bioelectricity and biomass creation settle on PMFC an engaging decision for the future environmentally friendly electrical energy. (Strik et al. 2008)

Bio systems contain non-living and living segments, interconnected to accomplish a bound together reason concerning food production, natural conservation, monetary improvement, and innovative headway. The process of photosynthesis which converts solar radiation into carbohydrates and further reactions converting carbohydrates finally into biomass is a series of interconnected transformations and a classical example of a biosystem. In comparable design, a PMFC captures the root exudate from photosynthesis and convert it to bioelectricity with a guide of microbial metabolism (Alocilja 2000).

Plants are the essential maker of a biological system. Being autotrophs, plants use sunlight based energy to create biomass with the guide of a special pigment present in the green parts of its leaves called chlorophyll.

Nonetheless, plants devour $40 \%$ of their vitality by itself, escorted by the exudation of staying half to the rhizosphere. Disintegration of organics to fetch electrons is materialized by microorganism populaces existing in the soil encircling rhizosphere. Further PMFC grasps this marvel, and electrons discharged by organisms are confined by anode locale. At the point when the electrons go throughout the heap and survive at the cathode finishing the circuit, power is delivered, purported "bioelectricity". Consequently, by the redox gradient between two electrodes, electricity is generated.

A PMFC can be seen as an extended variety of bio system feasibly structured. The bio control complex (plant) gets the outside info signal (daylight) to attain voltage. The bio process complex (microbial populace) lay hold of material assets (root exudates) and follows up them to deliver the yields (voltage). (Fig: 1) This structure is dependent upon unsettling influences, could potentially cause varieties in the yield and all the while, itself. In case of open-loop bio system, the active signal (sunlight) can be reshaped, thereby affecting the outputs (Strik et al. 2008).

This innovation involves multidisciplinary regions running from the investigation of microorganisms, plants, electrochemistry and different engineering fields. (fig :2)

In this study, we examine MFC by using Bacillus megaterium and sewage material and PMFC by using Azolla and Trigonella foenum. The fundamental target is creation of bioelectricity which implies less malicious to the earth. Sewage for example benthic is blend of natural and inorganic part. It furnishes with unconventional type of energy. Benthic soil contains network of organisms that are electrogenic and helpful in MFC activities (Guzman et al. 2010). Microbes produce bioelectricity from their natural metabolism by using the nutrient present in their environment. It guarantees ceaseless energy, long span support free bioelectricity. Sewage the untreated waste, that messes sanitation up is being dealt with MFC innovation.

Along this agenda, bestow of waste occur and best conception as bio electricity is brought up. Contrary, Bacillus megaterium is omnipresent in soil. Electrochemically active redox enzymes are present in bacteria as mediator less MFCs, at their outer membrane that transmit the electrons to external materials, as a consequence, needless of exogenous chemicals to accomplish electron transfer to electrode (Oh et al. 2004). 
Strain of megaterium is easy to cultivate and is source of bioremediation. It requires less maintenance and is easy to handle. It is very efficient and generates bioelectricity for longer period of time (Nagulapalli Venkata et al. 2017). (FG) is a plant seeds turned out to be verifiably utilized in cooking, herbal remedy, anti-microbial, anti-inflammatory, anti-oxidative, anti-cancer, anti-diabetic effects. Germination of Fenugreek vitals 5-10 days, while primary trifoliate leaf seems 5-8 days after germination. It is swiftly flourishing plant, specifically might develop on dry meadows, developed or arid terrains, slopes, planes just as field edges, however its vitality is a lot day light. India is a significant maker, with fenugreek creation in India got from various states. Rajasthan represents over $80 \%$ of India's yield. Azolla, a free-gliding water plant is another quickly developing plant, which can develop without nitrogen $(\mathrm{N})$ in water in view if a cooperative relationship with the nitrogen fixing endophytic blue-green cyanobacteria, Anabena azollae. Azolla species have been seriously concentrated because of their high development rates joined with high bioremediation productivity. Along these lines, the azolla and fenugreek species are picked for the forthright audit in any case, any of the earthbound and amphibian plant can be utilized to create bioelectricity (Taylor and Francis 2002).

Utilizing this adaptable innovation, towns and homesteads in creating nations could become independent, while industrialized countries could decrease their nursery impressions by drawing power from wetlands, nursery or bio-processing plants. This examination uncovers about the different advancements and applications by MFCs and PMFCs.

\section{METHOD AND CONSTRUCTION:}

\section{MFC of Microorganism}

- Many various designs are feasible for MFCs. Generally utilized and reasonable structure is a two - chamber MFC work in a conventional " $\mathrm{H}$ " shape which contains two chambers, an anode and cathode (Bond et al. 2002).

- The Bacillus megaterium acts as a biocatalyst present in the anaerobic anodic chamber while cathodic chamber contains $\mathrm{NaCl}$ solution for production of bioelectricity (Min et al. 2005).

- The two chambers are separated by salt bridge which contains agar agar and $0.1 \mathrm{M} \mathrm{NaCl}$ solution.

- The modulation of this structure is to pick a film that permits protons allying the chambers to forestall particle saturation.

- The most habitually utilized terminal in anode and cathode are made up of carbon materials containing: graphite pole are used for steadiness in microbial societies, high electric conductivity and tremendous surface area (Logan et al. 2006).

- On applying a resistor over the outside circuit, voltage drop over the resistor and current moving through the resistor is estimated with the assistance of a multimeter. (Fig:3)

\section{MFC of Benthic soil}

- The Benthic soil - MFC sticks to a similar fundamental standard of MFC.

- A single - chambered MFC was utilized with benthic soil.(Fig:4)

- Benthic soil was obtained from cesspits, and has numerous microorganism present in it (Lee et al. 2015).

- The bioelectrogenic cells arrangement, which are comprised by plastic with the accompanying measurements: $10 \mathrm{x} 8 \mathrm{x} 10 \mathrm{~cm}$, and inside an aggregate of $250 \mathrm{gm}$ of Benthic soil was housed (Aziz et al. 2013).

- The materials used for both electrodes formation were: graphite rod. $(6.0 \times 0.5 \mathrm{~cm})$ Anode electrode placed at base and cathode electrode placed at the uppermost part, both electrodes are attached with copper wire and that copper wires are connected variable resistor and monitored by a Digital multimeter, finally complete a circuit (Babu and Mohan 2012).

\section{Terrestrial PMFC}

- This construction of PMFC is done using terrestrial plant in a pot having tainted soil. The plant Trigonella foenum-graecum regularly known as Fenugreek is utilized in the accompanying development.

- A graphite sheet electrode of size $6 \mathrm{~cm}$ x $6 \mathrm{~cm}$ is used as anode and cathode. The anode is arrangement beneath the plant roots while the cathode is placed on the soil surface around the emerging shoot.

- A copper wire is drawn from both anode and cathode which is used to setup an external circuit. The anode transfers these electrons cathode which is in direct contact with air.

- As electrons move to cathode by means of copper wires utilizing outer circuit and the protons move towards the cathode from the soil (Strik et al. 2008).

- On applying a resistor over the outside circuit, voltage drop over the resistor and current moving through the resistor is estimated with the assistance of a multimeter.(Fig:5) 
- This construction of PMFC is done using aquatic plant Azolla. Lam. commonly known as mosquito fern.

- This construction requires 2 chambers, one chamber in which the Azolla is grown which is also known as the Anode of the cell and another chamber which consists of salt water which is also known as the Cathode of the cell.

- An oxygen pump is kept in the cathodic chamber to keep it constant oxygen rich.

- Both the chambers are internally connected by a salt bridge which is made using $2 \%$ Agar Agar solution $+0.1 \mathrm{M} \mathrm{NaCl}$ solution to prevent ion saturation and externally connected by copper wires woven into the graphite electrodes present in each chamber (Strik $e t$ al. 2008).

- As electrons move to cathode through copper wires utilizing outside circuit, the protons move towards the cathode from the salt bridge. On applying a resistor over the outside circuit, voltage drop over the resistor and current moving through the resistor is estimated with the assistance of a multimeter.(Fig:6)

\section{- RESULT AND MECHANISM:}

MFC and BMFC: The dialogue from methodology, explains that the three system each of BMFC and MFC of microorganisms are connected in series. The BMFC is single chambered while MFC of microorganisms is dual chambered. To escalate the voltage output the systems are connected in series. (Fig:7)

Both systems were perceived synchronically. By this exposition, we observed stately result.(Table:1 )

In the ambition of getting constitutive results, the setup was connected in series for couple of days. After 12th day, when gained potential voltage 1.5 Volts another cell of 1.5 Volts was connected with whole series. In the extension, An LED was affixed with whole system and a switch was joined. From the above cessation, we can say that by connecting the system in series we got tremendous results.

During the whole process, BOD and COD was measured of benthic soil. A single-chamber MFC was used with domestic sewage wastewater had $\mathrm{BOD}=110 \mathrm{mg} / \mathrm{L}, \mathrm{COD}=250 \mathrm{mg} / \mathrm{L}, \mathrm{TOC}=80 \mathrm{mg} / \mathrm{L}$. BOD( Biological Oxygen Demand) and COD (Chemical Oxygen Demand) are both measure out the amount oxygen needed to oxidise the Organic material available in a given sewage sample. The difference between them is: BOD being a test of the level of organic material that can be biologically oxidized while COD determines the amount of organic matter chemically. BOD and COD helps to facilitate the electron transfer from microbial cells to electrode. BOD can be used as sensors which help to directly measure the potential voltage. By BOD test the performance of the MFC can be monitored very closely and working of MFC can be improved.

\section{MECHANISM:}

Benthic soil is composed of organic and inorganic matter that comprises of innumerable diverse system of microorganisms that flourish on distinct different electron donors and acceptors. Anode is positioned below in the benthic soil in anaerobic condition and above it cathode is located under aerobic condition connected by external circuit.

The microbes will form the biofilm on the surface of anode, oxidize the organic and inorganic matter generating highly reduced biomolecules like NADH . These electrons produced through them are then transferred to anode. Further the electron moves to the aerobic area i.e. cathode. Then the oxygen is reduced when accepts electron and reacts with proton to form water molecule. In consequence, bioelectricity is generated. The difference in potential generated between oxidation and reduction reaction allows this process to be used as electric current.(Fig:8)

Anodic reaction: $\mathrm{C}_{2} \mathrm{H}_{4} \mathrm{O}_{2}+2 \mathrm{H}_{2} \mathrm{O} \rightarrow 2 \mathrm{CO}_{2}+8 e^{-}+8 \mathrm{H}^{+}(1)$

$$
\text { Cathodic reaction: } 2 \mathrm{O}_{2}+8 e^{-}+8 \mathrm{H}^{+} \rightarrow 4 \mathrm{H}_{2} \mathrm{O}(2)
$$

In case of MFC, it contains cathode and anode separated by proton exchange membrane connected by external circuit. On this planet there is a manifold of microorganisms with their distinctive metabolic pathways which sanction them to reduce oxidized metal such as iron oxide that carry respiration. Electrogenic microbes, which are able to breath metal compounds homogenous to other organisms. Microorganisms present in anodic chamber, metabolize the given organic substance and generate biomolecules such as NADH and generate electrons (e-) and protons $(\mathrm{H}+)$. On the outer membrane of bacteria, they have active redox enzymes through which electrons are transferred and through exogenous chemical they attain the electron moved to the electrode. Electrons are transferred to the anode by electron mediators or shuttles, by direct membrane associated electron transfer, or by so-called nanowires produced by the bacteria. In the cathode chamber is a terminal electron acceptor (usually oxygen) where protons and electrons form molecules of water. The electrons are conducted to the cathode by an external circuit, and protons are migrated through the salt bridge. Therefore, this whole process gives rise to bioelectricity.(Fig:9)

PMFC:

The three setups each of fenugreek and azolla were connected in series individually (Fig:10) and the results were noted. (Table:2

As per the previous words in methodology, both the system are assembled in opposition to each other i.e. the terrestrial is put on using single chamber while the aquatic is using dual chamber to compensate feasibility in work. In account of this, the progress is eventually noted on diurnal rhythm. In expectation of the fruitful result, the unabridged set of PMFC is bound together in series and is secured for 
couple of days for the static result. After gaining the potential difference by $1.50 \mathrm{~V}$ a cell of potential difference $1.5 \mathrm{~V}$ is connected with the continuation with L.E.D. and switch at one culmination point.(Fig:11)

As per the conclusion, we can say that the series connection leads to superior generation of electricity which gratifies our saying of green electricity and can conserve much of the world's energy.

\section{MECHANISM:}

As per the photosynthesis, plant utilizes photons as the light energy to form glucose as the vital component.

$$
6 \mathrm{CO}_{2}+12 \mathrm{H}_{2} \mathrm{O}+\text { light energy } \rightarrow \mathrm{C}_{2} \mathrm{H}_{12} \mathrm{O}_{6}+6 \mathrm{CO}_{2}+6 \mathrm{H}_{2} \mathrm{O}
$$

Organic matter is manufactured by the process of photosynthesis in plants from renewable sources like sunlight, and $\mathrm{CO}_{2} .70 \%$ of this organic matter leads as the Dead matter found in soil like root material, mucilage, lysates and exudates. Bacteria which lives on and around roots oxidize organic matter which releases $\mathrm{CO}_{2}$, protons, and electrons. [1] The reactions take place as below:

ANODE: $\mathrm{C}_{6} \mathrm{H}_{12} \mathrm{O}_{6}+6 \mathrm{H}_{2} \mathrm{O} \rightarrow 6 \mathrm{CO}_{2}+24 \mathrm{H}^{+}+24 e^{-}$

CATHODE: $1 / 2 \mathrm{O}_{2}+2 \mathrm{H}^{+}+2 e^{-} \rightarrow \mathrm{H}_{2} \mathrm{O}$

As per the earlier statement, the anode is tethered to cathode by virtue of external circuit and at the anode side which release protons is transited towards the cathode by the means of a membrane or spacer. The flow of electrons is directed via an external circuit i.e. from anode to cathode where water is formed by the reduction of oxygen along with electrons and protons.(Fig:12)

When PMFC, the bio- system is built, the condition of plant influences the enclosed soil and thus engendered output power changes subsequently. Nutrition fulfillment of bacteria by the photosynthesis process is the fundamental duty of plant. Due to that, an unsound plant will lower the performance of PMFC, that would dry up the nutrients. In this wise, estimation the growing flora in the similar environment can also be accomplished by keeping a track of output power. (Fig:13)

\section{DISCUSSION:}

Monetary development, computerization, and modernization for the most part rely upon the security of energy supply. Worldwide energy request is quickly developing, and, by and by, the overall concern is on the best way to fulfil the future energy request. Long haul prognosis demonstrate that the energy request will quickly increment around the world. Fossil fuels have been employed as imperative energy sources to access the energy demands. The fossil fuels produce ozone harming substances that profoundly influence nature and the group of people yet to come. The emanations to a great extent rely upon the outflow circumstances of essential power sources (i.e. plant's insertion fuel). The discharge element amidst the energy sources, petroleum products (i.e. oil, flammable gas and coal) exceptionally has emission factor. For energy generation, fossil fuels are chiefly employed as fundamental fuel.(Fig:14)

Taking into account that the significant segment of ozone harming substances (GHGs) is $\mathrm{CO}_{2}$, so this is a global concern about diminishing carbon effluents. On that wise, different approach possibly can be applied to diminish carbon outflows, for example, improvising sustainable power source arrangement and empowering mechanical developments. What's more, supporting components, for example, feed-in levies, inexhaustible portfolio guidelines and the tax policies are engaged by the government for the development of renewable energy generation and additionally enforcing energy use effectively for saving energy.

Majority of the countries have adapted the amenities that utilize sustainable sources to generate energy. Exorbitant utilization of nonsustainable energy sources akin to the significant use of elective power sources which leads to environmental changes. There are three essential inspirations that animate the development of sustainable power source advances: energy securities, economics impacts and $\mathrm{CO}_{2}$ emanation decrease. Another form energy distinctive from traditional power sources which also includes hydropower are termed as "alternative energy".

As of the late attention has been on sustainable powers sources. Strategy producers should advance inexhaustible assets (sun powered, wind, hydropower, biomass, and geothermic) for maintainable and neutral-carbon energy. Twentieth century energy framework can be mutated with brilliant framework as new dependable, astute, flexile, mutual web, and stabilized which empowers financial empowerment, collapse of environment, functionally adept power safety, also expanded user authority. While considering clean advances, 2 essential ideas for power innovation: power funding technologies, that alludes towards elective wellsprings concerning sustainable power sources (for example: air, sun-based force), also power proficiency advances, either such advances that are especially recruited for improvement of power usage effectiveness, (for example: cogeneration power plant, virtual power plant(VPP), smart meters). Necessary to notice, by changing power segment, also by supplanting regular power along sustainable power source which relates transformative to change in technologies, and farming business. 
Microbial fuel cells (MFCs) and Plant microbial fuel cell (PMFC) positively assures igneous energy scavenging which contributes perpetual, and concurrently maintainable energy granting lengthy duration .

\section{MFC AND PMFC AFFECTED BY THE FACTORS ARE:}

Microbial fuel cell (MFC) is advanced innovation, which will be utilized for power generation during the oxidation of natural substances introduced in the substrate. There are few factors that are significant because of their metabolism and the mediators which are used by them for transferring electron to the anode. There are different substrates which can be utilized as the wellspring of electron contributors in the MFC and oxidised by microorganisms. Working conditions for example temperature, ionic strength, $\mathrm{pH}$ of the mediums, construction and material of the cathode, anode and membrane could considerably affect power generation. Figure 15 summarises these factors. Designing the electrode is the greatest challenge in making MFC a scalable and cost effective technology. Recently, interest in the configuration of electrode material has steadily increased in studies for MFC. Over the past decade, a large number of electrodes have been explored extensively for MFC. It is important to recognize and consider these essential factors to have a highly efficient MFC.(Shanmuganathan and Rajasulochana 2018).

This investigation represents a PMFC as an engaging wellspring of supportable and sustainable energy source. Factors influencing the activity of PMFC have been exhibited as far as impact of plants, impact of organisms, and arrangement structure. (Fig:16) Research on PMFCs involves that performance of C4 pathways plants is better in PMFCs, anyway framework execution is subject to different elements like anode materials and working parameters. Plant and soil types are important factors for forming microbial networks that can at last modify the force yield. The pattern of voltage generation is influenced by the idea of exudation used by organisms. The morphology of roots and biomass, anode construction, and setup plan generally influence the bioenergy collect from PMFCs (Rachnarin and Roshan 2017).

\section{COMMERCIALIZATION OF MFC AND PMFC:}

Commercialization of any affluence technology is being dependant, when marketed and used by large amounts. For this, we have to focus on some parameter like technology, government sources, available sources, cost prices, education, instruments and facilities etc. the correlation between these parameters are shown in fig: 17.

\section{MAJOR PIT HOLES OF THE TECHNOLOGY AND SOLUTION:}

Highly assured technology for power generation by engaging waste material i.e. MFC and PMFC, abide with many challenges which obstruct its commercialization. Some major pit holes are as follows (Chaturvedi and Verma 2016).(Fig:18)

1. Xenobiotic and waste provide power density to MFC is comparatively less than pure carbon sources such as glucose. Thus this implies the major hindrance in management of waste and electricity generation for day to day purpose.

2. Wastes are cheap comparatively to the cost of pure for carbon sources so they cannot be engaged customarily for electricity generation.

3. A good understanding of plant-microbe relationship is the key to high quality performance of PMFC. Every plant is not able to produce electricity so selection of plant should be proper.

4. During the mounting of MFC and PMFC, the element usage for cathode/anode along with membrane is expensive that hampers commercial marketing.

\section{CONCLUSION:}

The PMFC and MFC are new and inventive innovation that has tremendous ambit for advancement and practical appropriateness in the advent future. With depth research, plants and microorganisms as a wellspring of power can possibly be novel innovation for development of green rooftops or biopanels in urban zones. Fruitful plan and improvement of PMFCs can be manageable wellsprings of bioelectricity of rural regions. Hence PMFCs has the extension to be actualized in different government and non government workplaces, singular families, networks and instructive foundations for advancement of a green and solid atmosphere, with the additional preffered position of renewable and sustainable bioelectricty. Likewise, electricity production from metabolism of microorganisms is a artistic technology in MFC. Along these lines ,to make genuine application conceivable, pervasive technology is highly imperative to make it cost effective with ease of maintainance, so that easily acceptable for the majority of people in eventual years. Thus, PMFC and MFC proved to competitive technology in the future, it might be accepted that it will increase an economy of scale benefit during the impending decade.

\section{LIST OF ABBREVIATIONS:}

MFC: Microbial Fuel Cell 
BMFC: Bacterial Microbial Fuel Cell

BOD: Biological oxygen demand

COD: Chemical oxygen demand

TOD: Total oxygen demand

Declarations

- Ethics approval and consent to participate: Not applicable

- Consent for publication: Not applicable

- Availability of data and materials: Not applicable

- Competing interests: The authors declare that they have no competing interests

- Funding: Not applicable

- Authors' contributions

Kruti Dave: Corresponding author(FC AND RH)

Parth Darji: (FC)

Fenie Gandhi: (RH)

Saumya Singh: (FC)

Digvijaysinh Jadav: (RH)

- Acknowledgements: Not applicable 


\section{REFERENCES:}

Asif, Muhammad \& Muneer, T. (2007) Energy Supply, Its Demand and Security Issues for Developed and Emerging Economies. Renewable and Sustainable Energy Reviews 11:1388-1413. doi: 10.1016/j.rser.2005.12.

Aziz Shaheen, Rehman Abdul, Syed Feroz, Shah Suhail, Soomro Anand, Parkash Anand (2013) PROTOTYPE DESIGNING AND OPERATIONAL ASPECTS OF MICROBIAL FUEL CELL - REVIEW PAPER. Science International 25(1): 49-56.

B.E.Logan, B. Hamelers, R. Rozendal, U. Schroder, J. Keller, S. Freguia, P. Aelterman, W . Verstraete, K. Rabaeyet al. (2006) Microbial fuel cells : methodology and technology. Environ Sci Technol 40:5181-5192. doi: 10.1021/es0605016.

Babu M. L \& Mohan S. V. (2012) Influence of graphite flake addition to sediment on electrogenesis in a sediment-type fuel cell. BioresourTechnol 110:206-213. doi: 10.1016/j.biortech.2012.01.064.

Behera M and Ghangrekar MM (2009) Performance of microbial fuel cell in response to change in sludge loading rate at different anodic feed pH. BioresourTechnol 100(21):5114-5121. doi: 10.1016/j.biortech.2009.05.020.

Blanco M I (2009) The economics of wind energy. Renewable and Sustainable Energy Reviews 13(6-7):1372-1382. doi: 10.1016/j.rser.2008.09.004.

Bodansky D (2005) Costs of Electricity. In: Nuclear Energy. Springer, New York, NY pp 559-577.

Bombelli P, Dennis RJ, Felder F, et al. (2016) Electrical output of bryophyte microbial fuel cell systems is sufficient to power a radio or an environmental sensor. $R$ Soc Open Sci.3(10):160249.doi: 10.1098/rsos.160249.

Bond D.R, Holmes D.E, Tender L.M, Lovley D.R et al. (2002) Electrode-reducing microorganisms that harvest energy from marine sediments. Science 295:483-485. doi: 10.1126/science.1066771.

Bruce E. Logan (2004) Peer Reviewed: Extracting Hydrogen and Electricity from Renewable Resources. Environmental Science \& Technology 38(9):160A-167A. doi: 10.1021/es040468s.

César I. Torres, Rosa Krajmalnik-Brown, Prathap Parameswaran, Andrew Kato Marcus, Greg Wanger, Yuri A. Gorby, and Bruce E. Rittmann (2009) Selecting Anode-Respiring Bacteria Based on Anode Potential: Phylogenetic, Electrochemical, and Microscopic Characterization. Environmental Science \& Technology 43(24):9519-9524. doi: 10.1021/es902165y.

Chae KJ, Choi MJ, Lee JW, Kim KY, Kim IS (2009) Effect of different substrates on the performance, bacterial diversity, and bacterial viability in microbial fuel cells. BioresourTechnol 100(14):3518-3525. doi: 10.1016/j.biortech.2009.02.065.

Chaturvedi V. \& Verma P. (2016) Microbial fuel cell: a green approach for the utilization of waste for the generation of bioelectricity. Bioresour Bioprocess 3:38. doi:10.1186/s40643-016-0116-6.

Deane J.P., O Gallachoir Brian, Mckeogh Eamon (2010) Techno-economic review of existing and new pumped hydro energy storage plant. Renewable and Sustainable Energy Reviews 14:1293-1302. Doi: 10.1016/j.rser.2009.11.015.

EC Alocilja (2000) Principles of Biosystems Engineering.

Fargione Joseph, Hill Jason, Tilman David, Polasky Stephen, Hawthorne Peter (2008) Land Clearing and the Biofuel Carbon Debt. Science (New York, N.Y.). 319:1235-1238. 10.1126/science.1152747.

Faruqui Ahmad, Harris Dan, Hledik Ryan (2010) Unlocking the [euro]53 billion savings from smart meters in the EU: How increasing the adoption of dynamic tariffs could make or break the EU's smart grid investment. Energy Policy, Elsevier. 38(10):6222-6231.

Guzman Juan, Cooke Keegan, Gay Marcus, Radachowsky Sage, Girguis Peter, Chiu Michael (2010) Benthic Microbial Fuel Cells: LongTerm Power Sources for Wireless Marine Sensor Networks. Proc SPIE. doi: 10.1117/12.854896.

Helder M., Strik D.P., Hamelers H.V. et al. (2012) The flat-plate plant-microbial fuel cell: the effect of a new design on internal resistances. Biotechnol Biofuels 5:70. doi: 10.1186/1754-6834-5-70.

Hill Jason, Nelson Erik, Tilman David, Polasky Stephen, Tiffany Douglas (2006) Environmental, Economic, and Energetic Costs, and Benefits of Biodiesel and Ethanol Biofuels. Proceedings of the National Academy of Sciences of the United States of America 103:11206-11210. doi: 10.1073/pnas.0604600103.

Huesemann, M.H. (2006) Can Advances in Science and Technology Prevent Global Warming?. Mitig Adapt Strat Glob Change 11:539577. doi: 10.1007/s11027-006-2166-0. 
Kaku N., Yonezawa N., Kodama Y. et al. (2008) Plant/microbe cooperation for electricity generation in a rice paddy field. ApplMicrobiolBiotechnol 79:43-49. doi: 10.1007/s00253-008-1410-9.1

Lee YS, An J, Kim B, Park H, Kim J, Chang IS (2015) Increased Power in Sediment Microbial Fuel Cell: Facilitated Mass Transfer via a Water-Layer Anode Embedded in Sediment. PLoS One 10(12):e0145430. doi: 10.1371/journal.pone.0145430.

Liu H., Ramnarayanan R., \& Logan B. E. (2004) Production of Electricity during Wastewater Treatment Using a Single Chamber Microbial Fuel Cell. Environmental Science and Technology 38(7):2281-2285. doi: 10.1021/es034923g.

Min B., Cheng S., Logan B. E. (2005) Electricity generation using membrane and salt bridge microbial fuel cells. Water Research 39(9):1675-1686. doi: 10.1016/j.watres.2005.02.002.

Nagulapalli Venkata KC, Swaroop A, Bagchi D, Bishayee A et al. (2017) A small plant with big benefits: Fenugreek (Trigonella foenum -graecum Linn.) for disease prevention and health promotion. Mol Nutr Food Res61(6) doi: 10.1002/mnfr.201600950.

NitisoravutRachnarin\&Regmi Roshan (2017) Plant microbial fuel cells: A promising biosystems engineering. Renewable and Sustainable Energy Reviews, Elsevier 76(C):81-89.

Oh SE, Min B, Logan BE et al. (2004) Cathode performance as a factor in electricity generation in microbial fuel cells. Env Sc Tech 38:4900-4904. doi: 10.1007/s00253-004-1845-6.

Petropoulos G.A.Taylor and Francis(2002) Fenugreek- The Genus Trigonella. London and New York.

Pimentel, D., Marklein, A., Toth, M.A. et al. (2009) Food Versus Biofuels: Environmental and Economic Costs. Hum Ecol 37:1. doi: $10.1007 / \mathrm{s} 10745-009-9215-8$.

RabaeyKorneel, Boon Nico, Siciliano Steven, Verhaege M., Verstraete Willy (2004) Biofuel Cells Select for Microbial Consortia That Self-Mediate Electron Transfer. Applied and environmental microbiology 70:5373-5382. doi: 10.1128/AEM.70.9.5373-5382.2004.

Shanmuganathan. P and Rajasulochana. P (2018) FACTORS AFFECTING THE PERFORMANCE OF MICROBIAL FUEL CELLS. International Journal of Mechanical Engineering and Technology 9(9):137-148.

Strik D.P.B.T.B, Hamelers H.V.M, Snel J.F.H, Buisman C.J.N et al. (2008) Green electricity production with living plants and bacteria in a fuel cell. International Journal of Energy Research 32(9):870-876. doi: 10.1002/er.1397. 
Figures

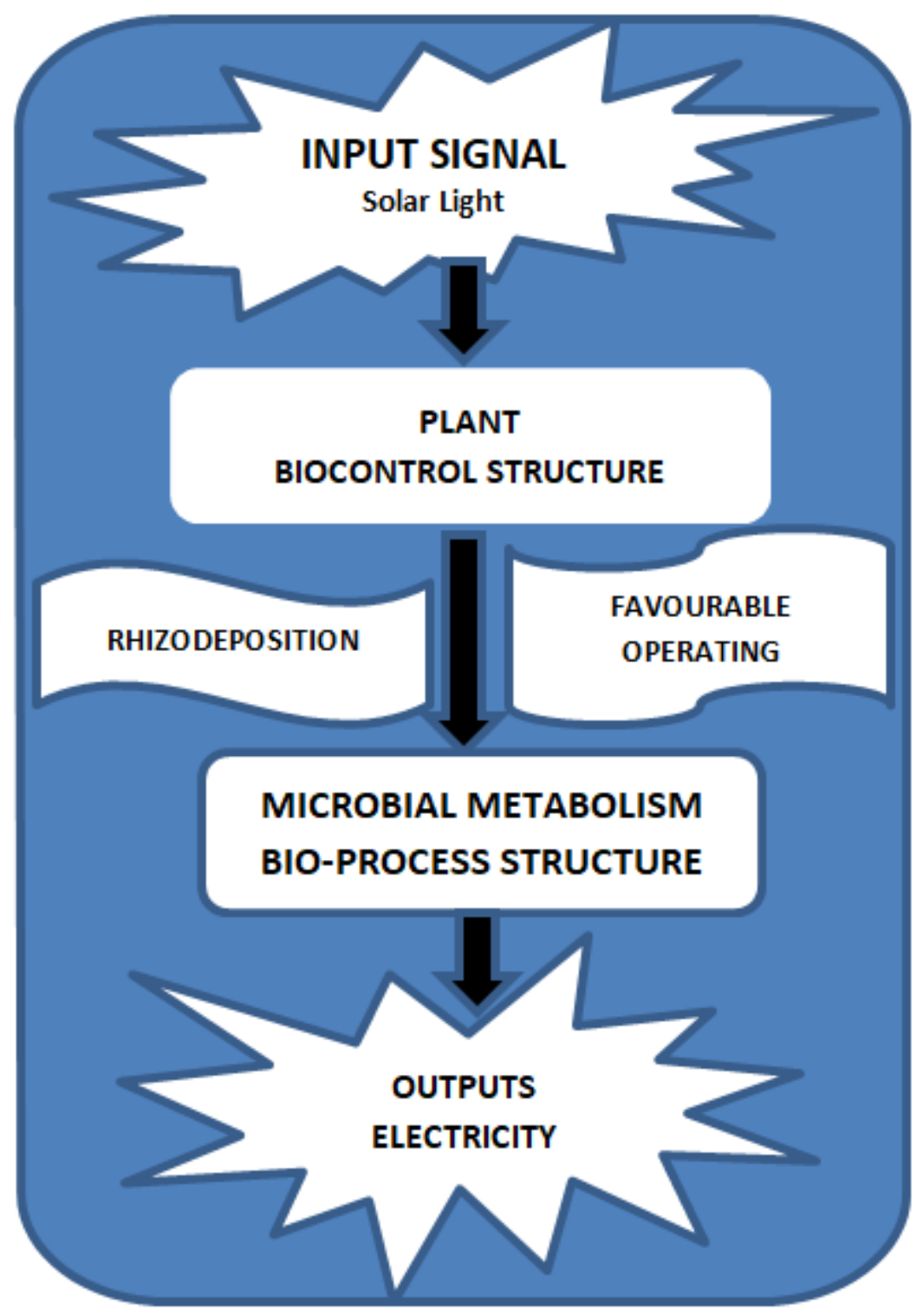

Figure 1

Bio process complex 


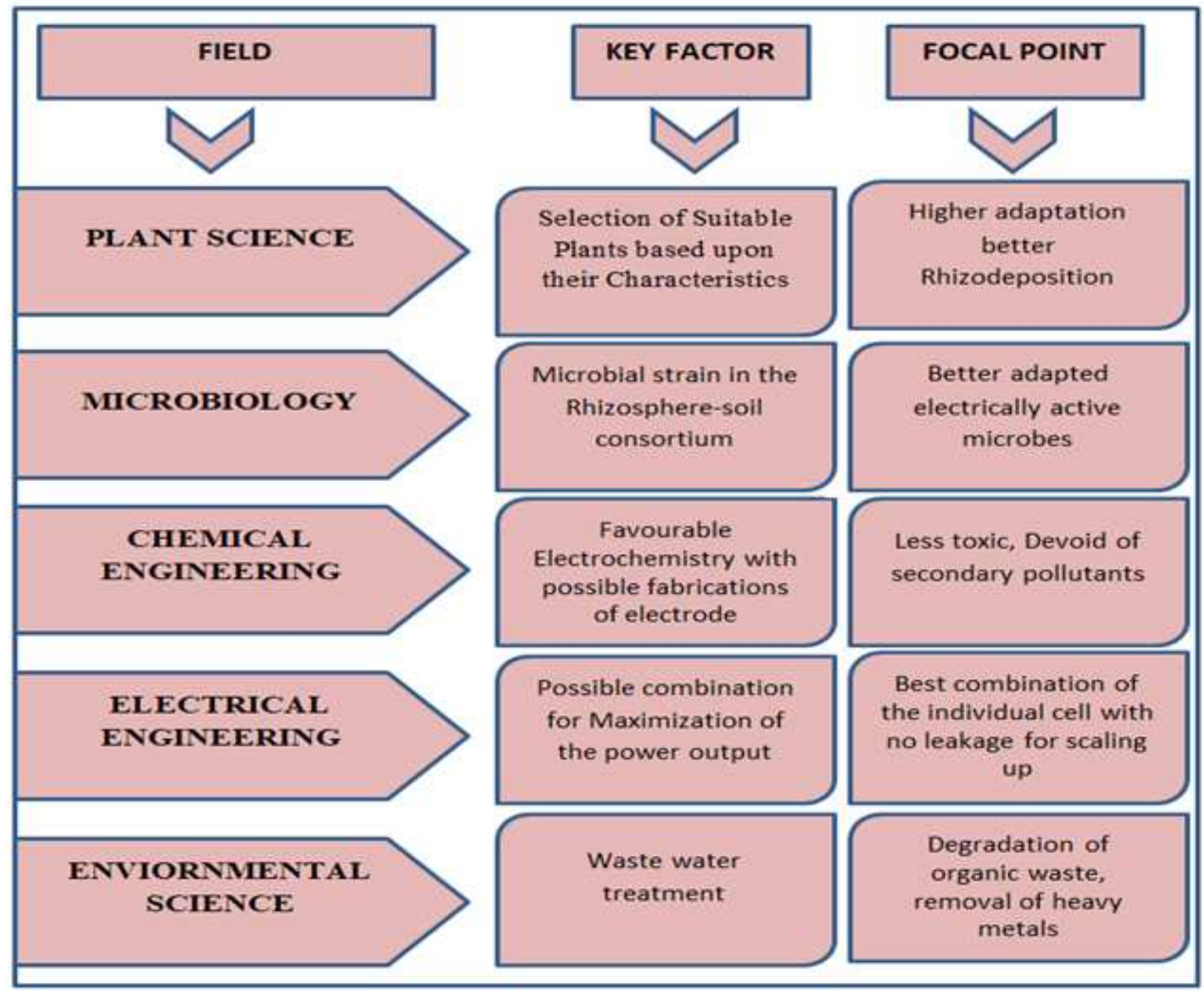

\section{Figure 2}

Field involved in PMFC mechanism 


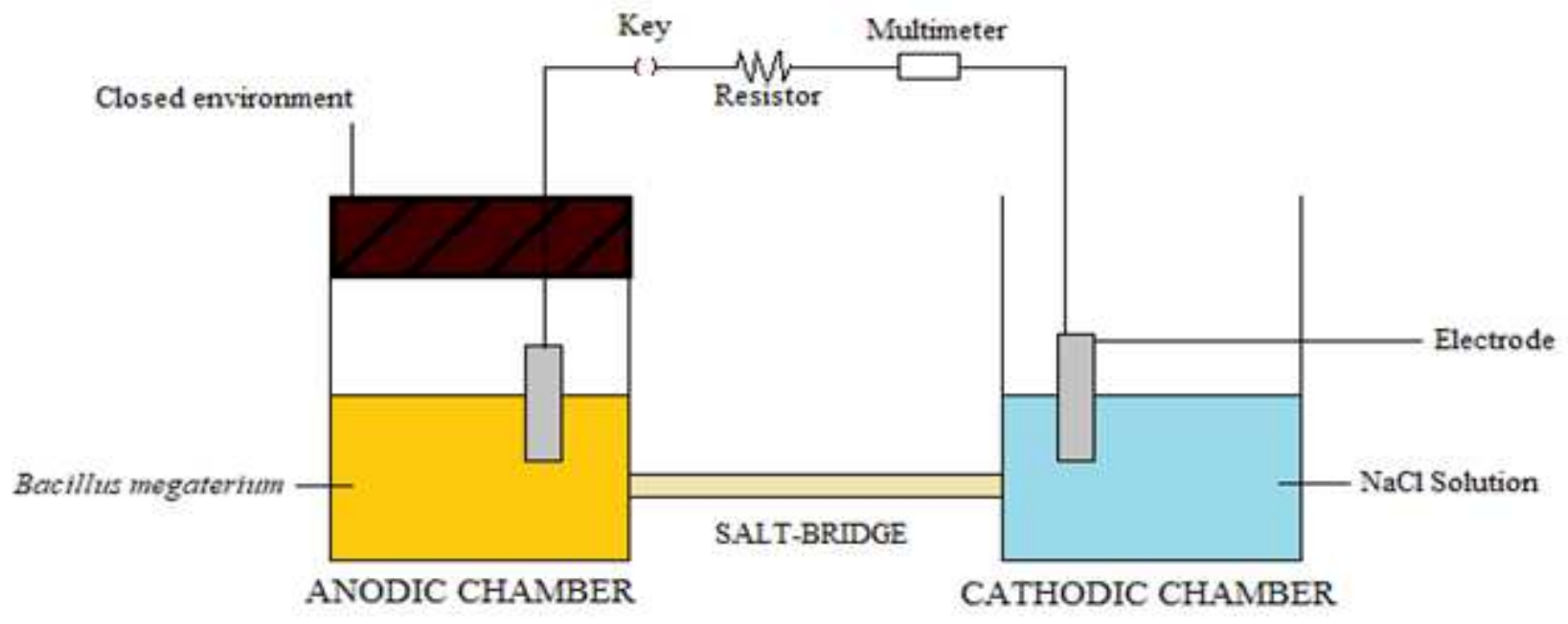

Figure 3

MFC of Microorganism

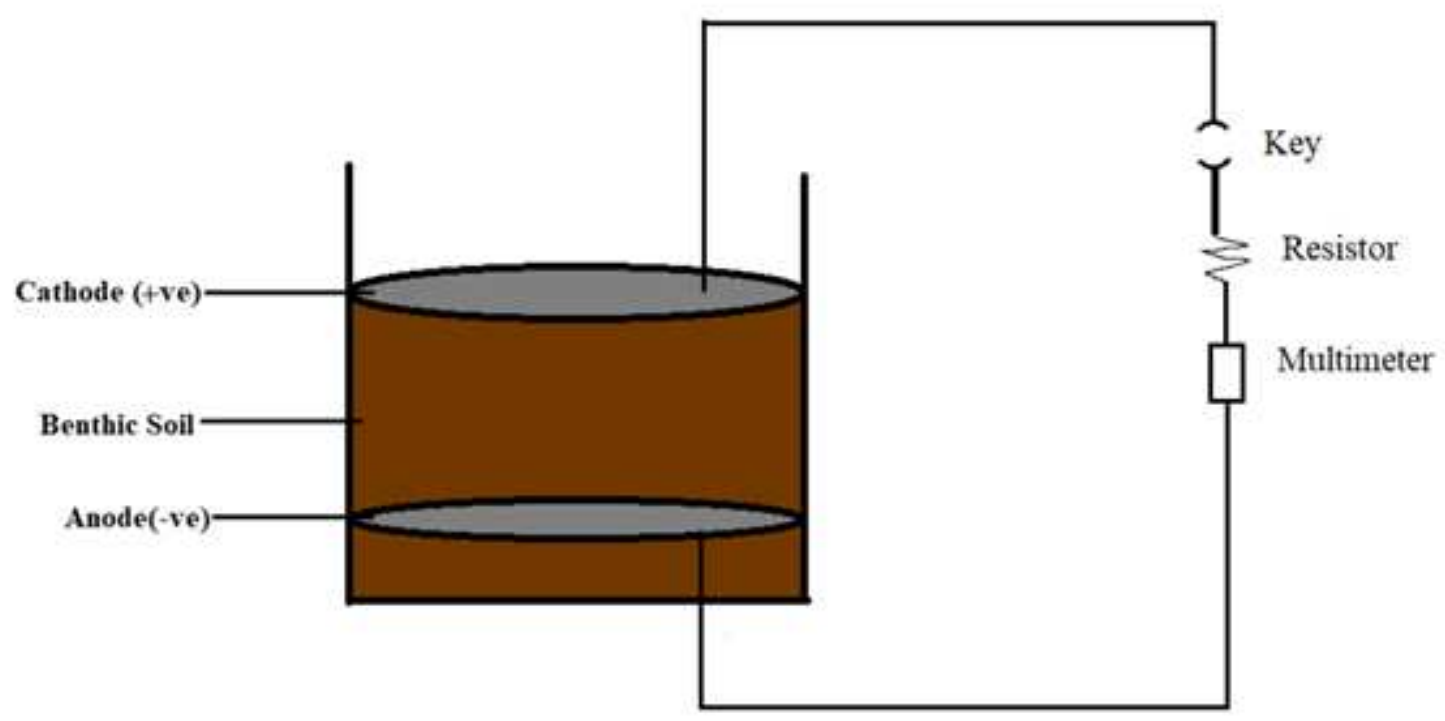

Figure 4

MFC of Microorganism 


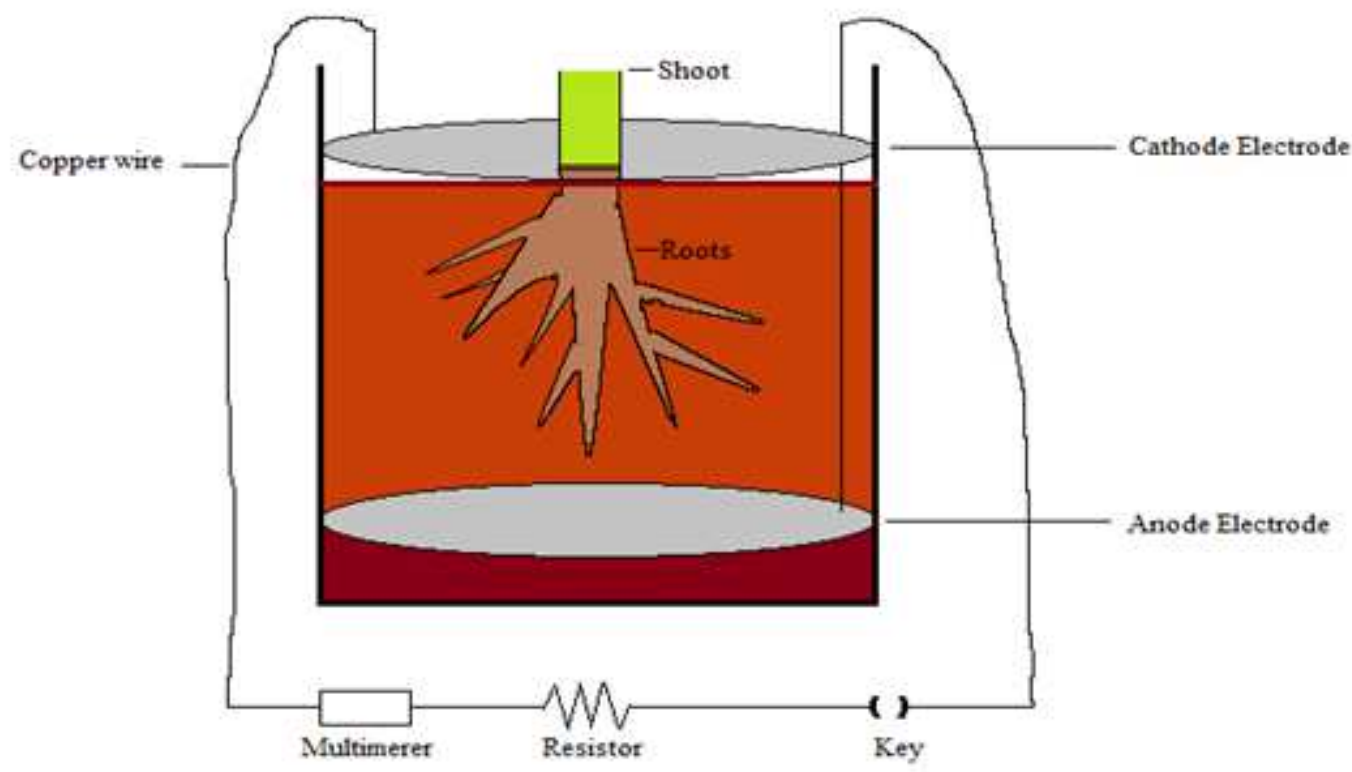

Figure 5

Terrestrial PMFC

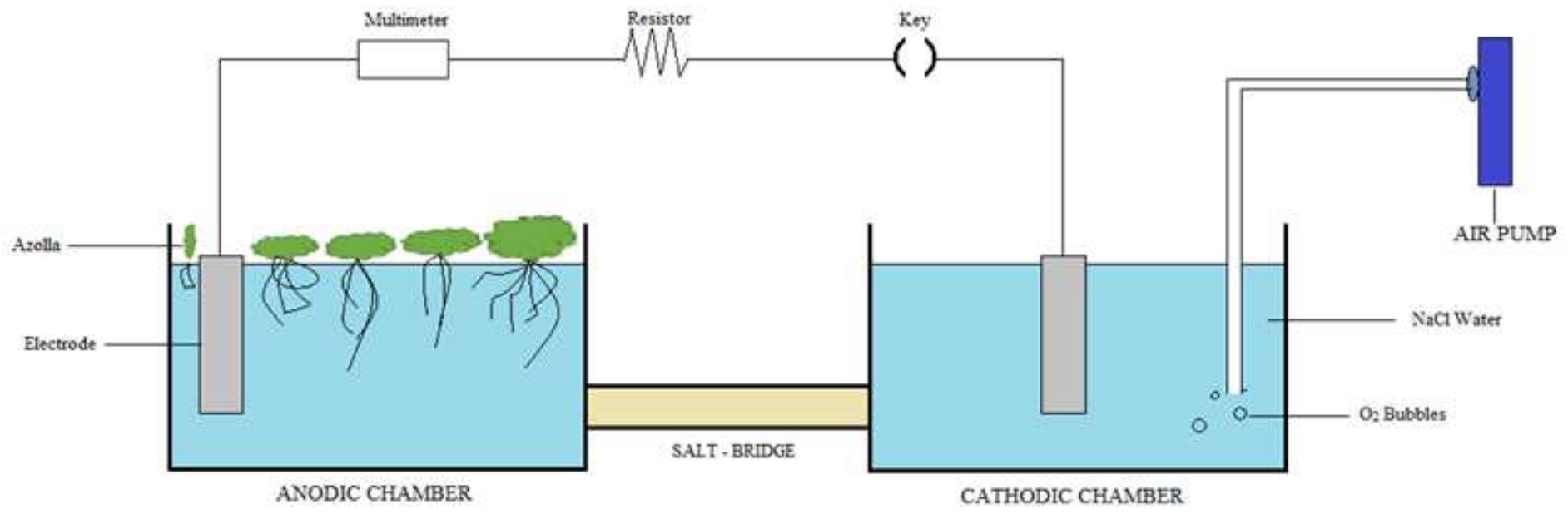

Figure 6

Aquatic PMFC 

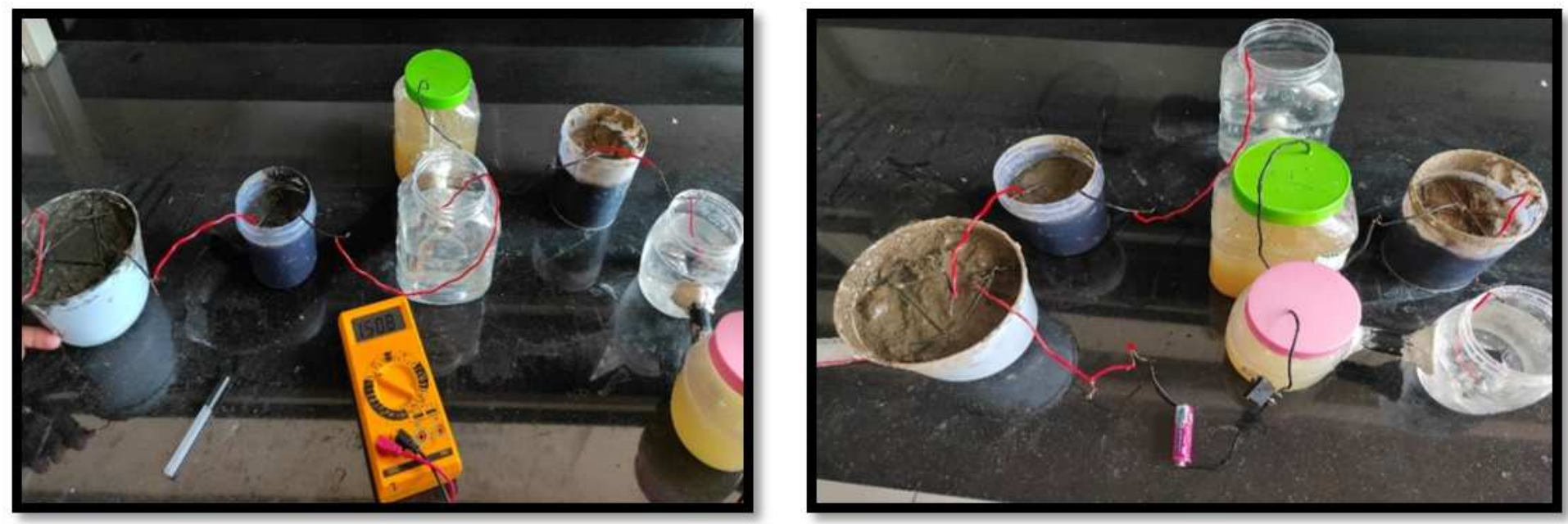

Figure 7

A [Series setup of all system] B [whole system connected in series with LED]

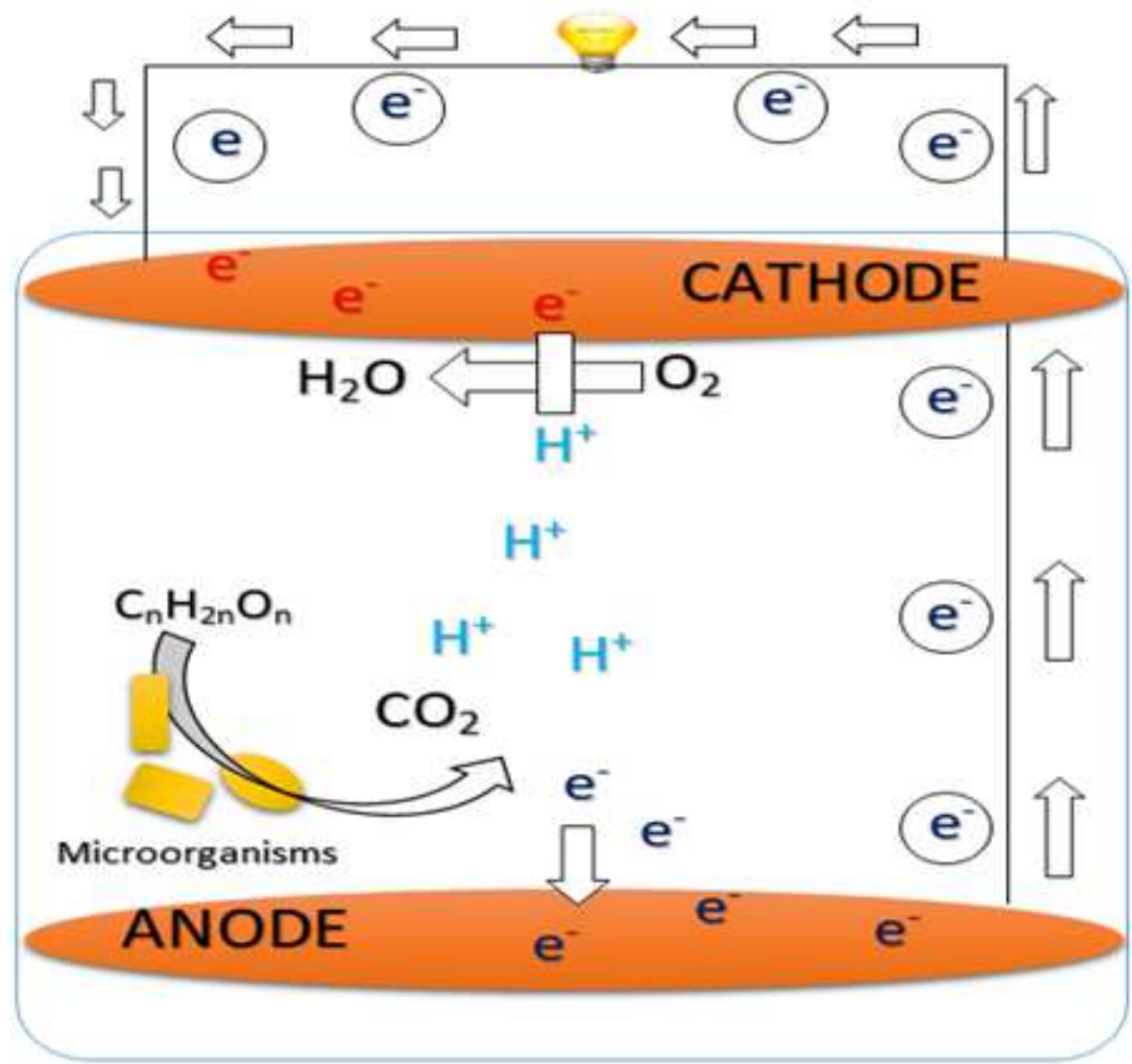

Figure 8

Mechanism of BMFC 


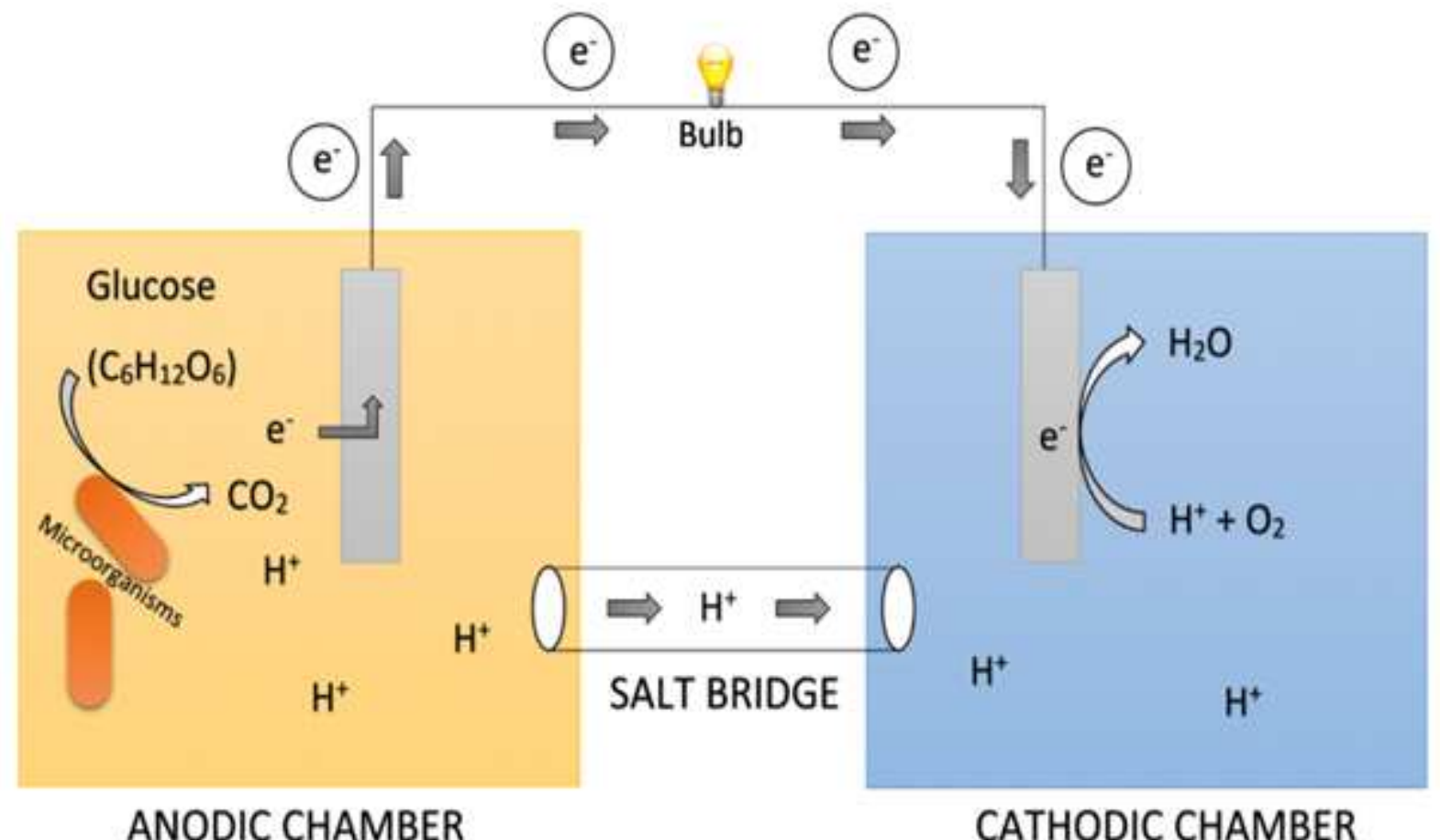

Figure 9

Mechanisms of MFCs
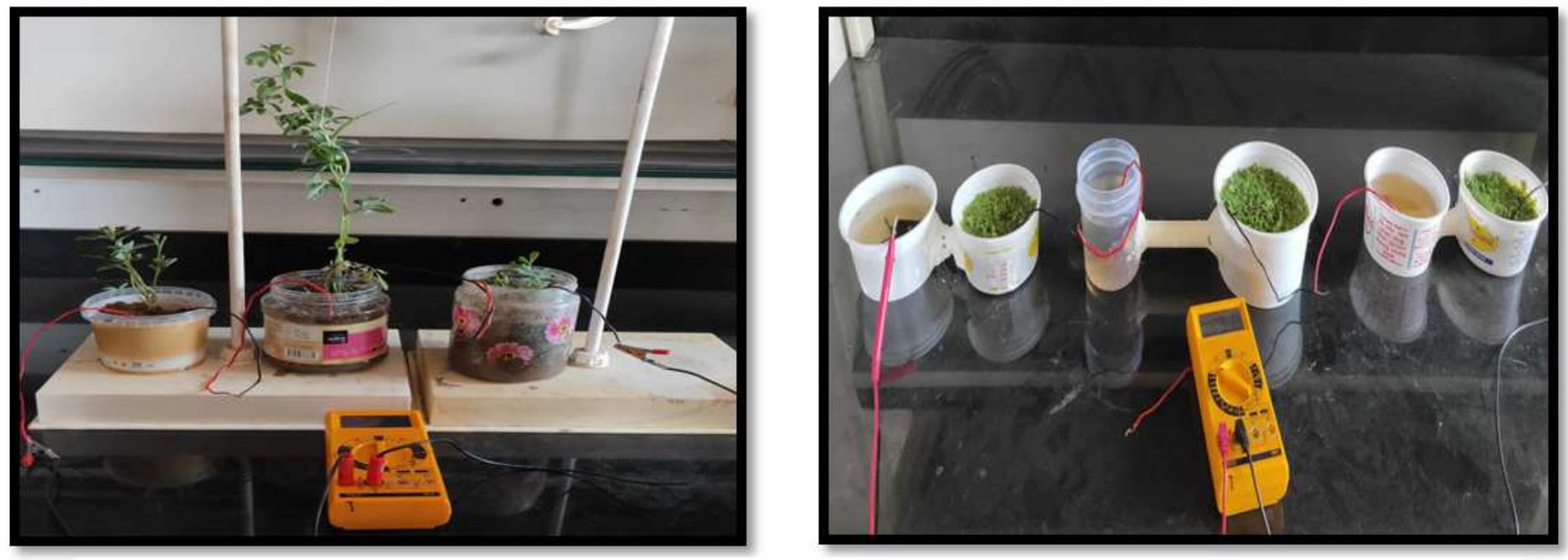

Figure 10

Series setup of Fenugreek and Azolla individually. 

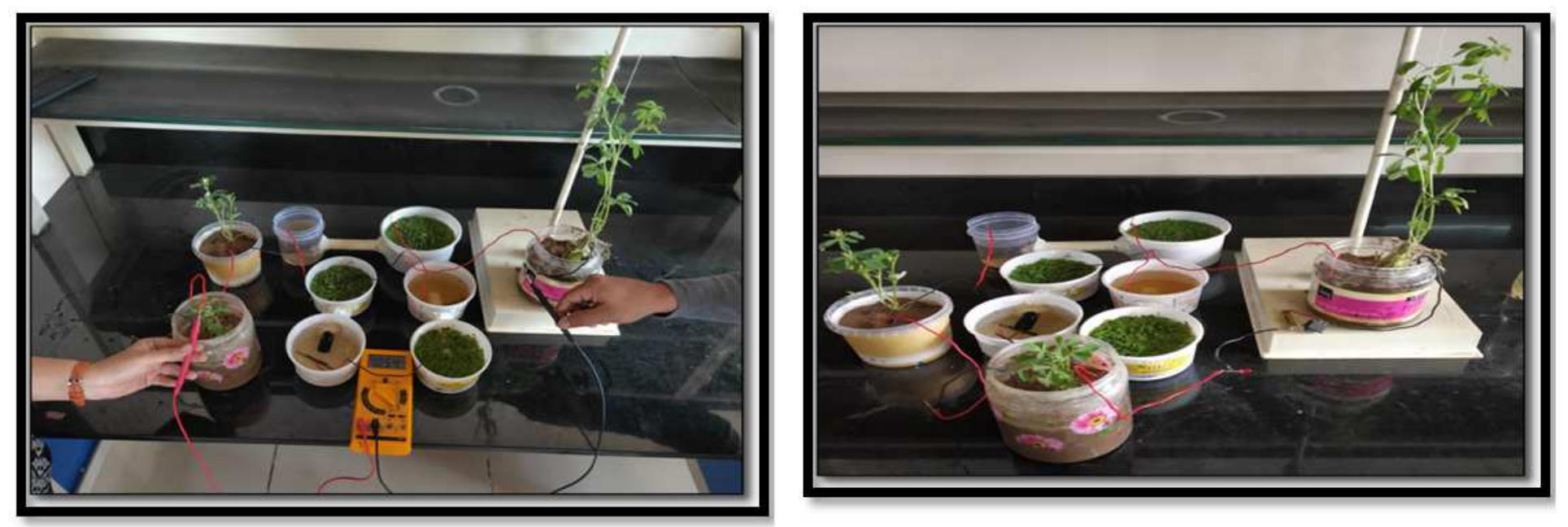

Figure 11

The compact series setup of same individual

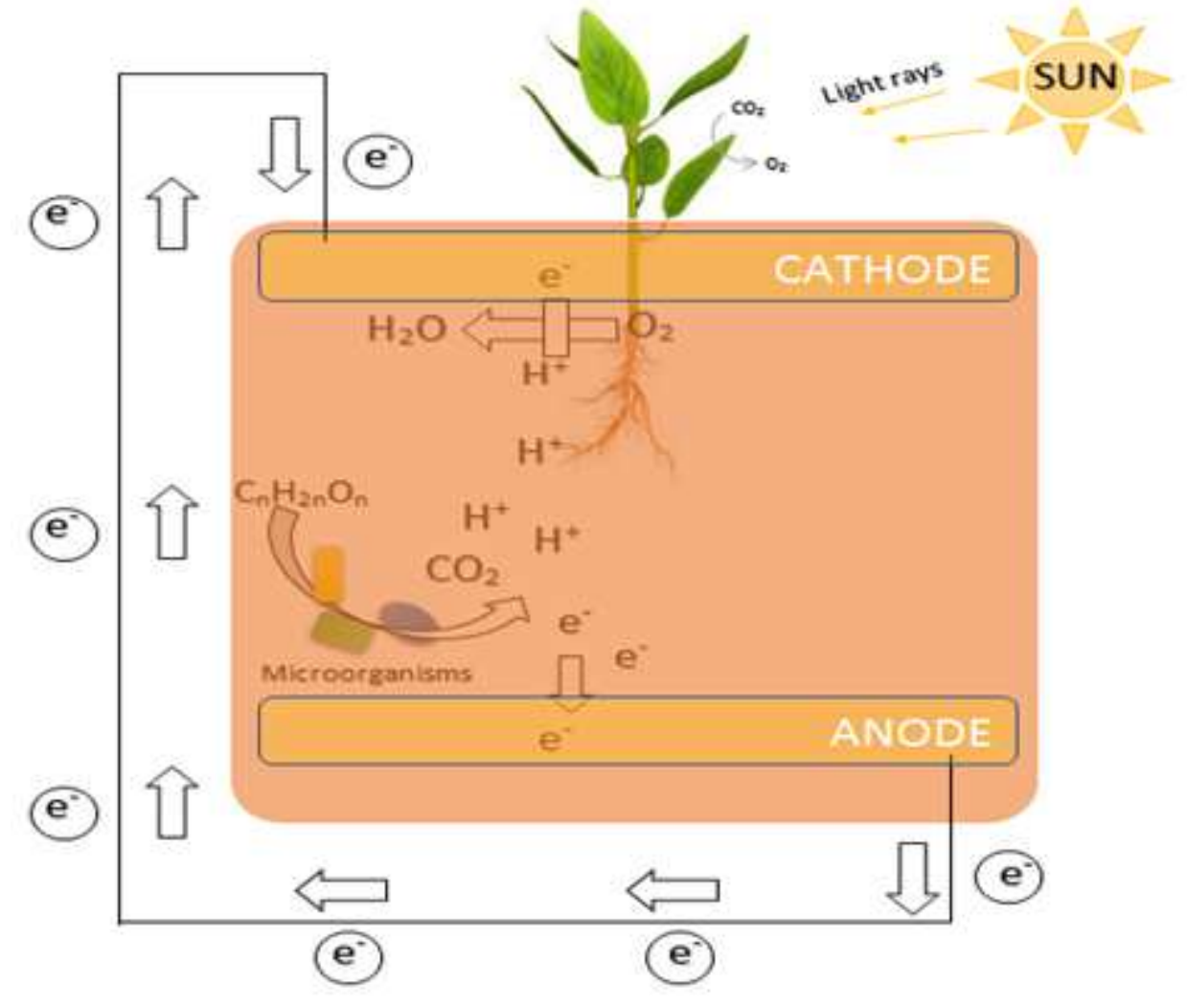

Figure 12

Mechanism of PMFCs (Terrestrial plant) 


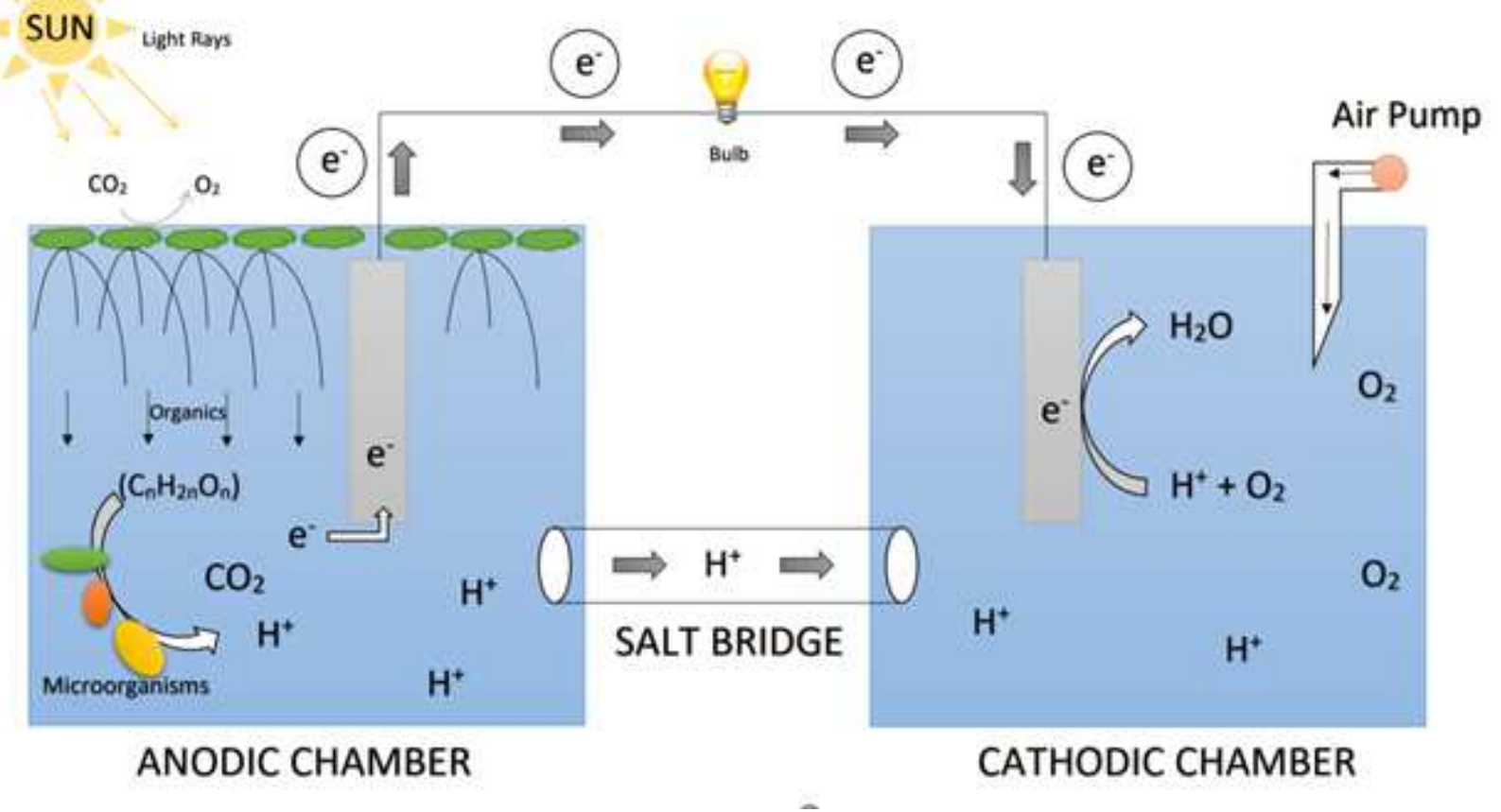

Figure 13

Mechanism of PMFCs (Aquatic plant)

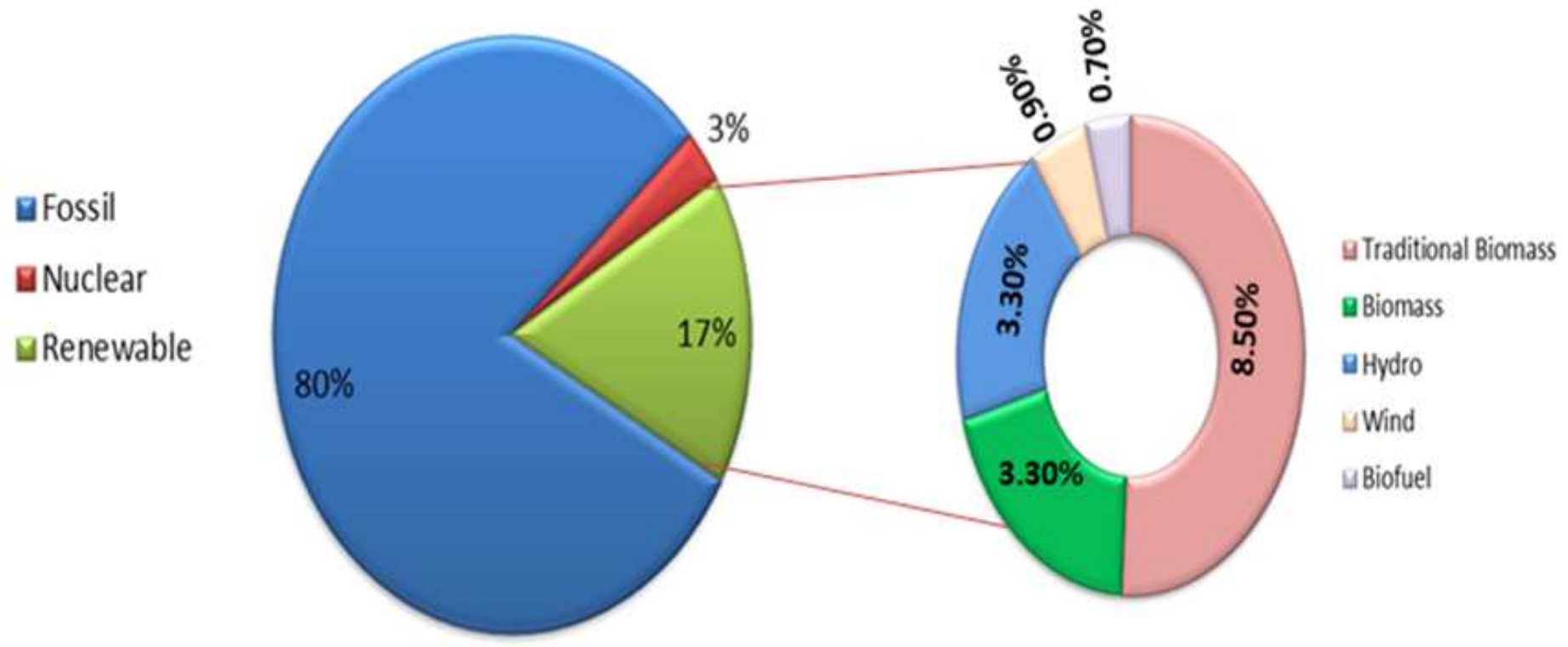

Figure 14

Worldwide Energy consumption and contribution of Sustainable energy 


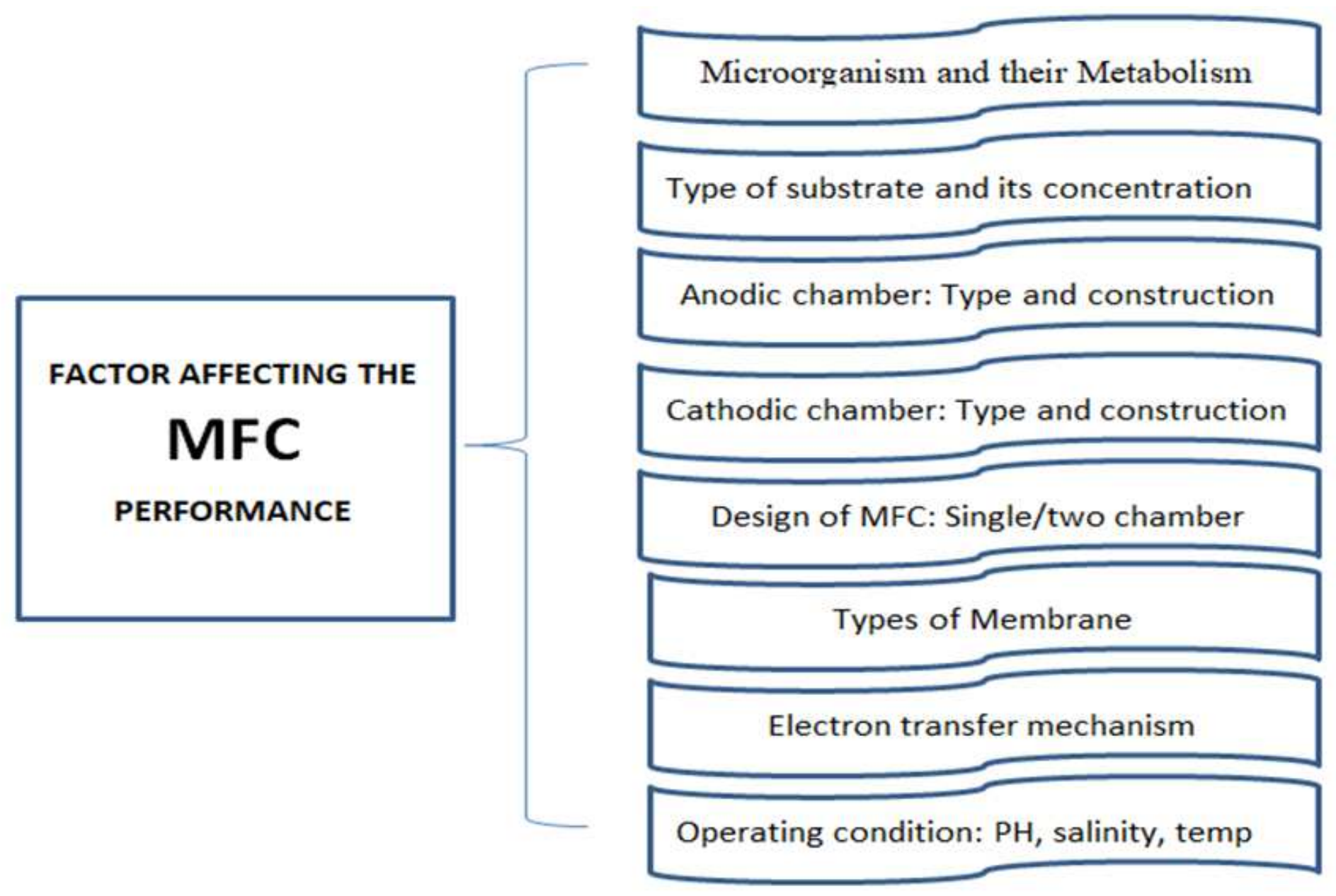

Figure 15

Factor affecting MFCs and BMFC 


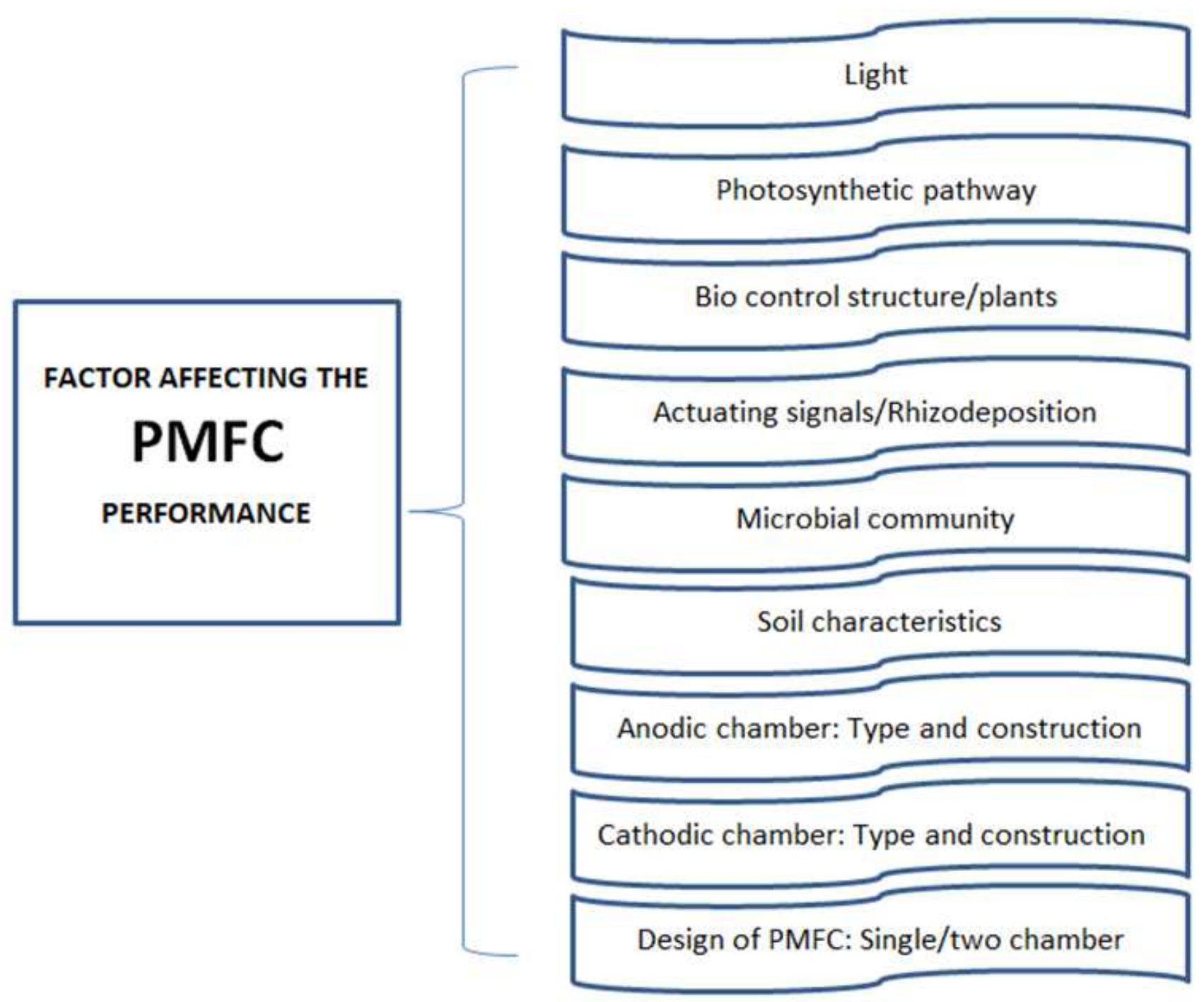

Figure 16

Factor affecting PMFCs 


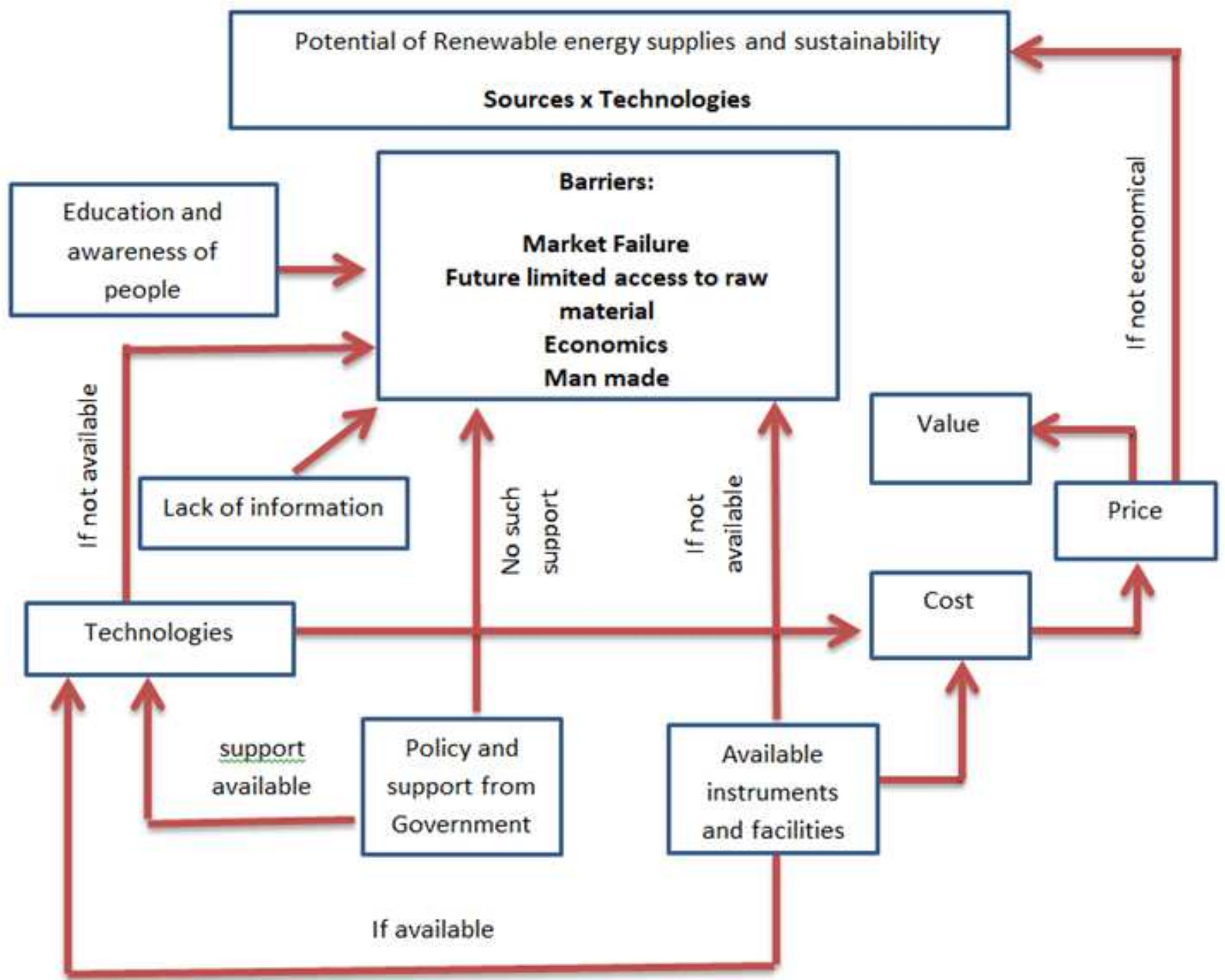

Figure 17

Parameters for commercialization 


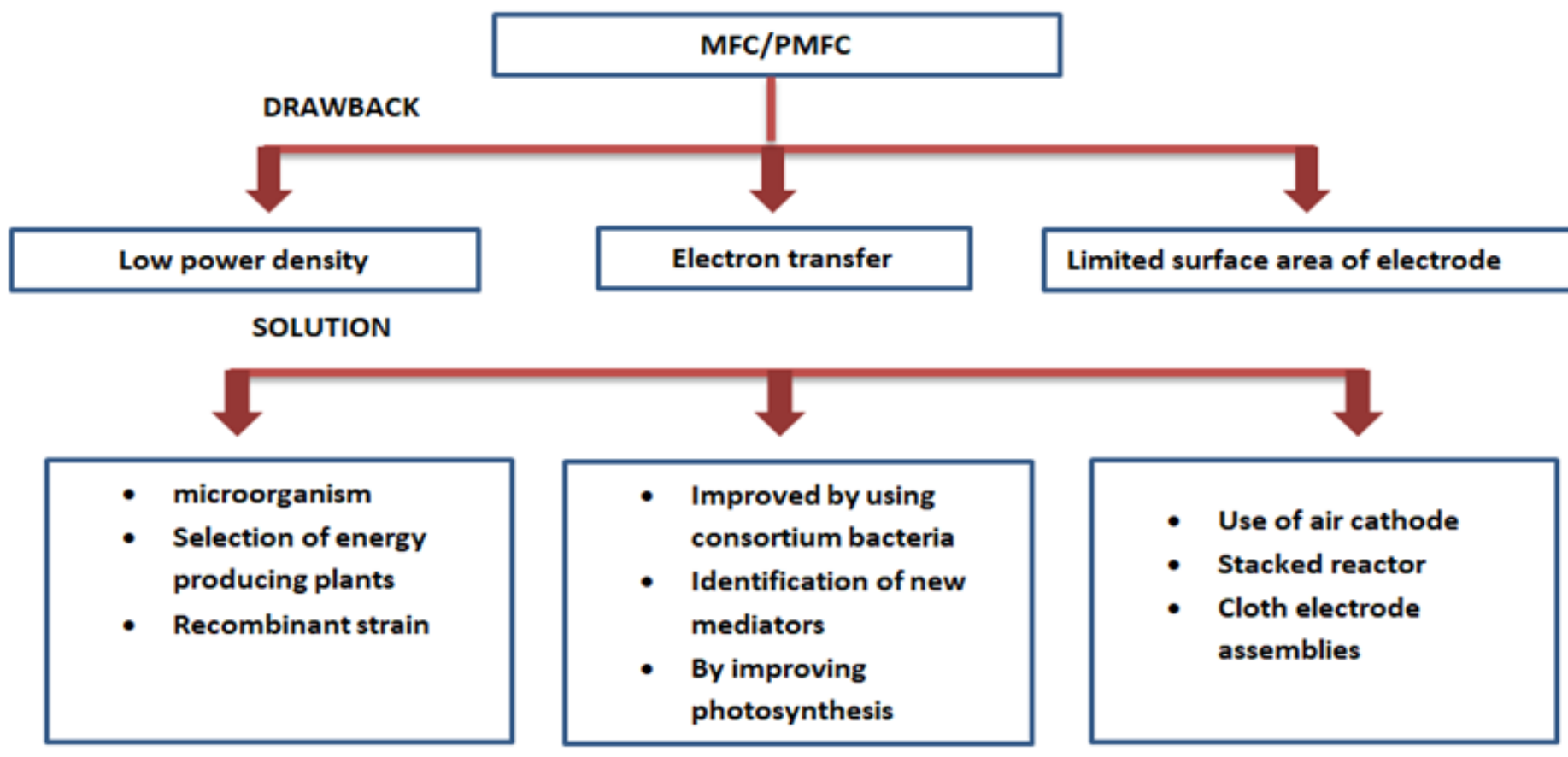

Figure 18

Outline of various drawbacks of MFC/PMFC and possible solutions which can help to enhance the efficiency of MFC/PMFC

\section{Supplementary Files}

This is a list of supplementary files associated with this preprint. Click to download.

- Table.docx

- GRAPHICALABSTRACT.docx 